\title{
الطموح المهني وعلاقته بالخدمات الارشادية لدى المرشدين التربويين
}

\author{
ا. م. د. ماللك فضيل عبدالل/ جامعة واسط \\ كلية التربية للعلوم الانسانية _ قعم العلوم التربوية و النفسية \\ malik.fdhail@gmail
}

07703252431

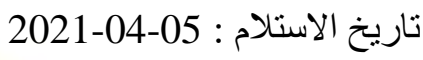

تاريخ القبول : 10-06

المستخلص

يهدف البحث الحالي التعرف على درجة الطموح المهني والخدمات الارشادية لدى المرشدين التربويين ، و الكثف

عن العلاقة الارنباطية بين الطموح المهني والخدمات الارشادية المرشدين التربويين ، وقد تحدد البحث الحالي بالمرشدين التربويين لكلا الجنسين في المدارس المتوسطة والاعدادية والثنانوية في محافظة واسط وذي قار للعام الدراسي (20202021) ، وقد تكوّن مجتمع البحث الحالي من (917) مرشد ومرشدة وبلغت عينة التحليل الإحصائي (200) مرشد ومرشدة ، وقد قام الباحث ببناء مقياس للطموح المهني وتبنى مقياس (المعموري ، 2018) للخدمات الارشادية وقد روعي في بناء وتبني المقياسين صدق البناء والثبات ، وحُلِّت البيانات إحصائياً باستعمال الحقيبة الإحصائية للعلوم الاجتماعية (SPSS) و أظهرت النتائج ما يأني:

1. أن المرشدين التربويين في محافظة واسط وذب قار لديهم انخفاض في تحقيق طموحهم المهني .

2. أن المرشدين التربويين في محافظة واسط وذي قار لايهم ضعف في تقديم الخدمات الارشادية بشكلها الصحيح و الفعال. 3. توجد علاقة ارتباطية طردية بين درجـات متغيري البحث الطموح المهني و الخدمات الارشادية لدى المرشدين التربويين

$$
\text { في محافظة و اسط وذي قار. }
$$

وقد وضع الباحث جملة من التوصيات والمقترحات على أساس النتائج التي خرج بها البحث الحالي . الكلمات المفتاحية للبحث : الطموح المهني ، الخدمات الارشادية ، المرشدين التربويين 


\section{Professional Ambition and its Relationship to Counseling Services for Educational}

\section{Counselors}

Assist. prof. Malik Fadheel Abdullah/ Wasit University

College of Education for Human Sciences/Department of Educational and Psychological Sciences malik.fdhail@gmail

07703252431

Receipt date: 2021-04-05

Date of acceptance: 2021-06-10

Abstract:

The current research aims to identify the degree of professional ambition and guidance services for educational counselors, as well as to uncover a relationship between professional ambition and educational counseling services for the educational counselors. The current research has identified educational counselors for both genders in intermediate Preparatory, and secondary schools in Wasit and Dhi Qar governorate for the academic year (2020-2021). The current research community consisted of (917) male and female mentors, and the statistical analysis sample reached (200) mentors, and the researcher built a scale for professional ambition and adopted the (Al Mamouri, 2018) scale for extension services. The data were analyzed statistically using the Statistical Portfolio for Social Sciences (SPSS), and the results showed the following:

1.The educational counselors in Wasit and Dhi Qar governorate have a decline in achieving their professional ambition.

2.The educational counselors in Wasit and Dhi Qar governorate have a weakness in providing guidance services in their correct and effective form.

3.There is a direct correlation between the degrees of the two variables for professional aspiration and the counseling services of the educational counselors in Wasit and Dhi Qar governorates. The researcher has put together a set of recommendations and proposals based on the results of the current research.

Keywords: for the research: Professional ambition, Extension services, Educational counselors 
يعد الارشاد النفسي احد قنوات الخدمة النفسية التي تقدم الى الافراد او الجماعات الاسوياء ، بهدف التغلب على بعض

الصعوبات التي تعوق توافقهم وانتاجيتهم ، كما يعد حلقة مكملة للتعليم والتعلم حيث يجعل من العملية التربوية والتعليمية اكثر فاعليـة ويسهـ في اعداد الطـلاب اعداداً متكاملاً ويسـاعدهم على تحرير طاقاتهم الكامنـة ليتمكنوا من الاستفادة من قدراتهم وامكاناتهم والتغلب على مشكلاتهم وبالتالي يؤدي الى تحقيق التوافق مع البيئة التي يعيشون فيها ويشجعه على تقديم الخدمات الارشادية (الاسدي ،2001: 24). ، وعلى الرغم من هذه المكانة فان سير العملية الارشادية لا يزال بطيئًا بثكل يجعله لا يستطيع ان ينهض بالمستوى العلمي والاجتماعي الى مستوى النجاح والرقي، والسبب يكمن في ضعف تقديم الخدمات الارشادية بشكلها الصحيح، وان النقص في القدرات والمهارات الذاتية لدى المرشدين في تقديم الخدمات الارشادية يترتب عليه اثار سلبية وهي الاحساس بالتعب والارهاق الجسمي والنفسي والامر الذي يجعلهم غير قادرين على انجاز المهام الموكلة اليهم وبالتالي تجعل البعض منهم غير مستقرين وغير مطمئنين في مهنهم مما يترتب علية اثار سلبية تتعك على طموحهم المهني في تحقيق نتائج مرغوبة من الرضـا و النجاح في العمل المدرسي والارشادي (Bandura,1997,p.3).هذا ما اكدته دراسة (الزهراني ،2012 ) ودراسـة (المعدوري ، 2018) ، ووجد الباحث مـا تعـزز الدراسـات مـن الزيـارات التي قـام بهـا الباحث على مجموعة من المدارس واجراء مقابلات شخصية مباشرة مـع المرشدين التربويين للتعرف على اهم المشكلات والصعوبات التي تواجههم واجراء دراسة استطلاعية على عدد اخر من المشدين للتعرف على اهم المعوقات ، وكان اغلب المرشدين التربويين يعانون من ضعف القدرة على القيام بالمهام الارشادية المناطة اليهم من تشخيص الحالات التي تواجه الطلاب في المدرسة وحل المشكلات التي يتعرضون اليها وغيرها من الحالات الاخرى التي تواجه الطلاب ، وكذلك تعرضهم لمواقف تثير لديهم مشاعر القلق والتوتر والمعاناة النفسية بسبب العبء الوظيفي وعدم تعاون ادارات المدارس معهم ومحدودية صـلاحيه وعدم توفر المكان المناسب لبعضهم ، وغيرها من الأمور التي تبعث اثار سلبية على طموحهم المهني ، وهذا بدوره يؤثر على انتاجية المرشدين التربويين في تقديم الخدمات الارشادية المناسبة ، واستتادا إلى ما تقدم فان مشكلة البحث الحالي تتضح بالإجابة على السؤال الاتي هل توجد علاقة ارتباطية بين درجة الطموح المهني والخدمات الارشادية لدى المرشدين التربويين ؟ 
تعد القوى البشرية المعدة والمؤهلة اساس تقدم الثعوب والأمم المختلفة ، واذا ما توفرت لها ظروف العمل المناسبة ، واشبعت حاجاتها البيولوجية والنفسية والاجتماعية فان دورها في الانتاج سيكون اكثر جدوى واكثر فاعلية (الطوالبة،2000: 59) ، وتعد مهنة الإششاد النفسي من ارقي المهن التربوية في العصر الحديث وان علاقة مهنة الإرشاد بالتربية علاقة مترابطة ومتكاملة ، إذ إن التربية الحديثة تعد مهنة الإرشاد التربوي جزءاً لا يتجزأ منها بل هي ركن أساسي من أركانها ، وقد أشار فون (Vaujhan) أنه لا يمكن التفكير بالتربية بعيداً عن الإرشاد إذ يتضمن الإرشاد عمليتي التعلم والتعليم وتعديل السلوك وتتضمن التربية عملية التوجيهه والإرشـاد (الزبيدي ،2001 :29) ، وان للخدمات الارشـادية النفسية اهمية كبيرة حيث يحتاجها كل طالب ويهتم بها ويشارك في توفير هذه الخدمات كل العاملين في مؤسسة التربية والتعليم، لذا فان الارشاد النفسي يحظى بمكانة خاصـة في كل كتب الارشـاد النفسي التي تركز على الارشـاد في المؤسسـة التربويـة وعليه فمن الضـروري ان تقدم خدمات التوجيه والارشـاد النفسي في المدرسة لإنجاز تلك المهام الإرشادية بصورة فعالة (زهران،1988: 42). ويـرى جبسون (Gibson) أن المرشد هو الثخص المؤهل الوحيد داخل المدرسة والذي تم إعداده للخدمات الإرشادية الفردية والجمعية وبناء الخطط الإنمائية والوقائية والعلاجية للمسترشدين والمرشد الفعال له هويته ويعرف من هو وماذا يريد من الحياة ويعرف ما يقوم به ويعرف ما هو أساسي وجوهري في عمله، والمرشدون الفعالون قادرون على إعطاء المساعدة ويتمتعون بقدرات ومهارات ارشادية عالية تمكنهم من تقديم الخدمات الإرشادية وكذلك لديهم الاستعداد للتغير والمرونة بدلاً من الثبات والجمود (الخواجا،2009: 15) ، ويعد الطموح المهني من المتغيرات التي لها تأثير مهم حياة المرشد التربوي ويلعب دوراً بارزاً في التوافق والتكيف النفسي والاجتماعي في مجال عمله ، وللطموح المهني اهمية كبيرة في حياة المرشد التربوي بحيث يجب ان يكون الطموح يتتاسب مع امكاناته وقدراته والبيئة التي يعيش فيها ، والمرشد الطموح يتميز بالتفاؤل تجاه مستقبله ويستطيع التغلب على الصعوبات التي تواجهه (البادري ، 2011 :402). ويرى الباحث ان تقديم الخدمات الارشـادية داخل المؤسسـة التربويـة يقترن حدوثها بدرجـة الرضـا والاستقرار والتكيف النفسي والاجتماعي للى المرشدين التربوين في بيئة العمل فضـلاً الى الخبرات والقدرات والمهارات الارشـادية التي يمتلكها لا يبقـى 
امسامهم سوى الابداع وانجاز المهام المناطـة اليهم بكل كفاءة وفاعلية في تقديم الخدمات الارشادية للطلبة داخل المؤسسات

التربوية وهذا بدوره يؤدي الى نجاح العملية الارشادية .

وبناءاً على ما تقدم يمكن أيجاز أهمية هذا البحث بالآتي :

الأهمية النظرية :

1. تأتي اهمية البحث من اهمية العينة المرشدين التربويين لانهم قادرين على تطوير المجتمع ولزم زمام المستقبل والمضي

فيه تقدماً.

2. تتاولها لموضوع الطموح المهني الذي يعد من اهم السمات التي ادت الى التطور السريع الذي شهده العالم في الآونة

الاخيرة فهو الدافع الذي يقوم بثحذ الهمم وترتيب الافكار للارتقاء بمستوى الحياة من مرحلة الى مرحلة اخرى متقدمة .

3. تتاولها لمفهوم الخدمات الارشادية التي تقدم خدمات نفسية للطلبة لتساعدهم في انسب الاختيارات في المجالات كافة

التربوية منها والاسرية والمهنية .

4. تعد الدراسة الاولى تتاولت الطموح المهني وعلاقته بالخدمات الارشادية لاى المرشدين التربويين على حد علم الباحث.

-

1. الاستفادة ادوات البحث والنتائج التي توصـلها اليها مـن قبـل وزارة التربيـة مـن اجل تقديم كل عوامل نجـاح العمليـة الارشادية.

2. تعدّ هذه الدراسة اضافة للمكتبات العراقية والعربية ، خاصةُ لم يعثر الباحث على دراسة جمعت بين متغيرات البحث .

$$
\text { - - أهدف البحث:- }
$$

1- درجة الطموح المهني لدى المرشدين التربويين في محافظة واسط وذي قار

2- درجة الخدمات الارشادية لدى المرشدين التربوين في محافظة واسط وذي قار •

3- الكثف عن علاقة بين الطموح المهني والخدمات الارشادية لدى المرشدين التربويين محافظة واسط وذي قار . 
يتحدد البحث الحالي على المرشدين التربويين لكلا الجنسين في المدارس المتوسطة والاعدادية والثانوية في محافظة واسط وذي

$$
\begin{aligned}
& \text { قار للعام الدراسي (2020-2021). } \\
& \text { - - تحديد المصطلحات:- } \\
& \text { اولاًا- الطموح المهني فعرفها كلا من:- }
\end{aligned}
$$

1- دسوقي (1990 ): هو المعيار الذي يحكم به الفرد على ادائه الخاص سواء النجاح او الفشل في بلوغ ما يتوقعه لنفسه (

$$
\text { القطناني ، 2011: } 45 \text { ) ) }
$$

- - ميعرف الباحث الطموح المهني نظرياً : بأنه قدرة المرشد التربوي على تحقيق أهدافه المستقبلية في ضوء قدراته وامكاناته في مجال عمله .

- ويعرفه اجرائياً : هي الدرجـة الكلية التي يحصل عليها المرشد التربوي من خلال أجابته على فقرات مقياس الطموح المهني

$$
\text { المستخدم في البحث الحالي · }
$$$$
\text { ثانياً- الخدمات الارشادية فعرفه كلا من: }
$$

1- الجمعية الامريكية للإرشاد النفسي (ASCA, 1980): "تلك الخدمات النفسية و الاجتماعية التي تقدمها جهات متخصصة

بالصحة النفسية والخدمات الاجتماعية والتربوية الى الافراد والعوائل والجماعات لتساعدهم في حل مشكلاتهم وهذه الخدمات

يقدمها اشخاص متخصصين في الارشاد وعلم النفس (6SCA, 2016 (المعموري ، 2018 : 13) •

- التعريف النظري للخدمات الارشادية : اعتمد الباحث تعريف الجمعية الامريكية للإرشاد النفسي (ASCA, 1980) ، وبناءاً

$$
\text { على التعريف المعد من قبل (المعدوري 2018) }
$$

- التعريف الاجرائي للخدمات الارشادية : هي الدرجة الكلية التي يحصل عليها المرشد التزبوي من خلال أجابته على فقرات مقياس الخدمات الارشادية المستخدم في البحث الحالي • الفصل الثاني

$$
\text { - - - مفهوا :الاطار النظري: }
$$


يعد الطموح المهني من اهم السمات التي ادت الى التطور السريع الذي شهده العالم في الآونة الاخيرة فهو الدافع الذي يقوم بشحذ الهمم وترتيب الافكار للارتقاء بمستوى الحياة من مرحلة الى مرحلة اخرى متقدمة ، ومـادام الطموح موجود عن الانسان فلا يوجد سقف للتطور العلمي والمهني لأنه من العوامل المهمة المؤثرة بما يصدر عن الانسان من نشاطات وافكار (محمد ، 2001: 16). ويعد الطموح المهني من العوامل الهامة المميزة للشخصية ، كما ان خبرات النجاح توثر ايجابياً في رفع درجة الطموح المهني ، فلأنسان عندما ينجح في امر ما فان ذلك يزيد من ثقته بنفسه ويرفع درجة طموحه في تحقيق حاجات اخرى ، ومعرفة الافراد بطبيعة طموحهم والعوامل المؤثرة فيها يجعلهم يحاولون موائمة قدراتهم وامكانياتهم مع هذه الطموح مما يترتب عليه عدم شعورهم بالإحباط والفشل جريو ،2001: 21).

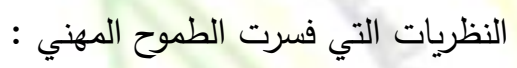
اولاً : نظريةادلر : n يركز ادلر على فكرة كفاح الفرد للوصول الى السمو والارتفاع تعويضاً عن مشاعر النقص ، ويعتبر ادلر الانسان كائناً اجتماعياً تحركه دوافع اجتماعية في الحياة فهو له اهدافه بالحياة يسعى الى تحقيقها وقد استعمل عده مفاهيم منها : 1- الذات الخلاقة : وتعني ذات الفرد التي تدفعه الى الخلق والابتكار • 2- الكفاح في سبيل التفوق : وهو اسلوب حياة تتضمن نظرة الفرد للحياة من حيث التفاؤل والتشاؤم • 3- الأهداف النهائية : حيث يفرق الفرد الناضج بين الأهداف النهائية القابلة للتحقق والأهداف الوهمية والتي لا يضـع الفرد فيها

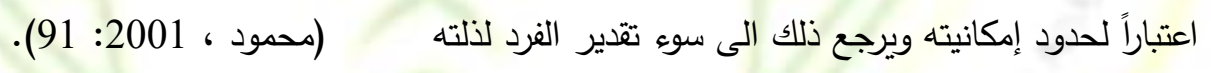

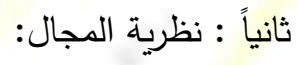

يرى كيرت ليفين ان هنالك عدة قوى وتعد دافعة وتوثر في درجة الطموح منها : 1- عامل النضـج : كلما كان الفرد اكثر نضجاً اصبح من السهل علية تحقيق الطموح لديه وكان له القدرة على التفكير في الغايات والوسائل على حدا سواء .

2- القدرة العقلية : كلما كان الفرد يتمتع بقدرة عقلية اعلى كان في استطاعته القيام بتحقيق اهداف اكثر صعوبة . 
3- النجاح والفثل : النحاح يرفع درجة الطموح ويشعر صاحبة بالرضـا اما الفشل فيؤدي الى الاحباط وكثيراً ما يكون معرقلاً

$$
\text { للتقدم في العمل - }
$$

4- نظرة الفرد الى المستقبل : توثر نظرة الفرد الى المستقبل وما يتوقع ان يحققه من اهداف في مستقبل حياته وعلى اهدافه

$$
\begin{aligned}
& \text { الحاضرة (النمري ، 1997: 34). } \\
& \text { - الخدمات الارشادية : }
\end{aligned}
$$

يمثل الإرشاد النفسي احد المجالات التطبيقية لعلم لنفس الحديث ، الذي يهدف إلى تحقيق سعادة الفرد وتطوره ، ويهدف الإرشاد النفسي إلى مساعدة الفرد على فهم نفسه وقدراته وإمكاناته من خلال علاقة واعية مخططة تهدف للوصول بها إلى السعادة وتجاوز المشكلات التي يعاني منها من خلال دراسته لشخصيته ، جسمياً وعقلياً وانفعالياً واجتماعياً، حتى يستطيع التوافق والتكيف مع نفسه ومجتمعة ومع الآخرين (الزبيدي ، 2001 :12) • ويعد الإرشاد النفسي احد قنوات الخدمة النفسية التي تقدم للأفراد او الجماعات بهدف التغلب على بعض الصعوبات التي تعترض سبل الفرد او الجماعات وتعوق توافقهم وإنتاجيتهم ، وتعد الخدمات الارشـادية بانها خدمات نفسية تقدم للطلبة لتساعدهم في انسب الاختيارات في المجالات كافة التربويـة منها

$$
\text { والأ. نظرية التحليل النفسية والمهنية }
$$

تتمتع هذه النظرية بأهية تاريخية لكونها تمثل بداية الإرشاد النفسي، ولان بعض مفاهيمها تكرر في النظريات الأخرى. ويعد(Freud) المؤسس الحقيقي لهذه النظرية (الصمادي، 1993: 52). ومع ان تطبيق النظرية التحليلية في مجال الإرشاد النفسي ليس بالأمر السهل، ألا ان فهم نظرية (Freud) يساعد المرشد على فهم اثر العمليات اللاشعورية على السلوك، كما يساعد المرشد في استقصاء آليات الدفاع التي يستخدها المرشد ومن خطوات الخدمات الارشادية التي يقدمها المرشد وفق نظرية

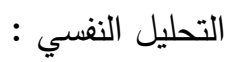

1- العمل على طمأنة المسترشد وتأكيد ثقته بنفسه وتكوين علاقة قائمة على الفهم والتقبل. 2- تطهير النفس من الخبرات، والأشياء المكبوتة عن طريق التفريغ الانفعالي والتداعي الحر. 3- تفسير ما يكثف عنه التداعي الحر بأسلوب منطقي ولغة مفهومة للمسترشد. 
4- إعادة التعليم وبناء العادات السليمة تدريجيا. (زهران، 1988: 116).

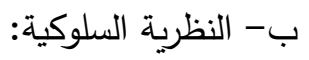

تعود جذور هذه النظرية إلى العالم الفسيولوجي الروسي بافلوف (Pavlov) الذي اكتثف ما يسمى بالإشراط الكلاسيكي ، وتعتمد النظرية السلوكية في منطلقاتها الأساسية على مبادئ نظرية التعلم وخاصة تلك التي تعرف بسيكولوجية المثير والاستجابة. ومن أهم رواد نظرية التعلم (ثورندايك) و (سكنر) و (واطسون). طبتت مفاهيم هذه النظرية في مجالات الإرشاد والعلاج النفسي من قبل (ولبي) و (دولارد وميللر). معظم السلوك الإنساني من وجهة النظرية السلوكية هي متعلمة، وهي بمثابة استجابات لمثيرات موجودة في البيئة، وقد اهتمت هذه النظرية بالسلوك من حيث كيف نتعلمه وكيف يتم تعديله او تغيره ، ينطلق الإرشاد في النظرية السلوكية من عدة أسس منها:- التعزيز، والانطفاء، والتعميم، والتميز (جبريل، 1992: 368). خطوات الخدمات الارشادية التي يقدمها المرشد وفق نظرية السلوكية: تقوم عملية الإرشاد في النظرية السلوكية على الأمور الآتية: 1- القياس: تستهدف هذه الخطوة تحديد ما يفعله المسترشد في الوضع الحالي، أي قياس المستوى الحالي للسلوك، لمعرفة مدى حدوث التحسن في الاتجاه المرغوب به، مقارنة مع المستوى الحالي للسلوك.

2- وضع الأهداف: يصاغ الهدف السلوكي على نحو قابل للقياس، ويمثل السلوك المرغوب به، والذي نسعى إلى تحقيقه من خلال العملية الإرشادية.

3- تتفيذ الإجراءات: تحديد الإجراءات التي بواسطتها يمكن الوصول إلى الهدف المرغوب به، والإجراءات التي يمكن استخدامها هي: تعديل السلوك، التعاقد السلوكي، التعزيز الرمزي، تقليل الحساسية التدريجي، والمعالجة بالتنفيذ....الخ. 4- التقييم والإنهاء: التقييم في العملية الإرشادية عملية مستمرة، فالمرشد يقيم فاعلية السلوك الإششادي المستخدم أثناء تطبيقه Lafleur, ) كي يتأكد من فاعليته، وبناء على ذلك يعمل المرشد على تعديل الأسلوب المستخدم في ضوء مدى فاعليته $\cdot(1979$, p. 233 ج · نظرية الذات : (20) يعد (Rogers) من أهم ممثلي نظرية الذات والتي تعتبر من اشمل النظريات في الإرشاد لارتباطها بأشهر طرق الإششاد والعلاج النفسي ، ألا وهي الإرشاد المتمركز حول المسترشد ويرى(Rogers) بان للى كل إنسان قوة نمائية موجبة تدفع به نحو 
الأفضل ، ويحاول الإنسان الوصول إلى أعلى درجة ممكنة من النمو، هو ما يسميه (Rogers) بتحقيق الذات ، هذه القوة النمائية تتجه بالإنسان لكي يصل إلى أقصى درجة تسمح بها قدراته في جوانب النمو المختلفة : الجسمية والعقلية والاجتماعية والانفعالية ومن خطوات الخدمات الارشادية التي يقدمها المرشد وفق نظرية الذات :

1- الاستكشاف والاستطلاع: أي التعرف إلى مصادر قلق وتوتر المسترشد، وتحديد الجوانب الايجابية والسلبية في شخصيته. 2- توضيح القيم وتحقيقها: يساعد المرشد المسترشد على زيادة فهمه وإدراكه لقيمه الحقيقية بهدف التعرف إلى التتاقض فيما بينها، وتوضيح الفرق بين القيم الحقيقية والقيم الزائفة للمسترشدين. 3- تعزيز الاستجابات والمكافأة: يوضـح المرشد مدى التقدم الايجابي ويقويـه لدى المسترشد كخطوة أولية للتغلب على مشكلاته

$$
\text { د- نظرية العلاج الواقعي: }
$$

ترى نظرية العلاج بالواقع أن دوافع السلوك الإنساني هي دوافع داخلية توجهها حاجات بيولوجية موروثة، ويشترك في هذه الحاجات جميع الناس، وهذه الحاجات هي:- (حاجة الإنسان إلى ان يحب، وحاجته إلى الإحساس بالقيمة، وحاجته إلى التمتع بالحياة، وحاجته إلى ان يكون حرا في تحديد مصيره). إذ اننا نولد وليس لدينا القدرة على إثباع حاجاتنا، ولكن من خلال عمليات التتشئة الاجتماعية يكتسب الإفراد المهارات الضرورية اللازمة لإشباع هذه الحاجات. فعندما يحرم الفرد من حاجة معينة ولمدة زمنية فانه يعيش حالة من التوتر ينتج عنها مخاوف مرضية وسلوك لا اجتماعي وقد تصل في بعض الأحيان إلى المرض النفيي (Shilling, 1984, p. 114). خطوات الخدمات الارشادية التي يقدمها المرشد وفق نظرية العلاج الواقعي : يقوم الإرشاد في نظرية العلاج بالواقع على ثلاثة مفاهيم أساسية تحكم سلوك الإنسان هي : المسؤلية والواقع والصحيح، فالسلوك المسئول من شأنه أن يساعد الفرد على إثباع حاجاته بطريقة لا تحرم الآخرين من إشباع حاجاتهم أيضا، وينظر إلى السلوك المسئول على انه هو الذي يولد السعادة وليس ناتجا عنها، اعتبر(Glasser) ان الوصول إلى السلوك المسئول هو الهدف الأكبر للعلاج بالواقع. أما بالنسبة للمفهوم الثاني (الواقع) يتطلب أن يفهم الناس العالم الذي يعيشون فيه بما فيه من مشكلات وعقبات، وان حاجاتهم يجب أن تثبع بصورة مسئولة في إطار الحدود التي يفرضها الواقع، أما بالنسبة للمفهوم الثالث (الصحيح) فهو يثير إلى المعيار الموضوعي الذي يستخدمه الناس في الحكم على سلوكهم بأنه صحيح او خطأ، وبذلك 
فأن الجوانب الأخلاقية لسلوك الفرد تعتبر جانبا هاما أثناء عملية الإرشاد ، وإن دور المرشد في نظرية العلاج الواقعي يتحدد بكونه مربيا ومعلما وصديقا، فهو يهدف إلى إعادة تربية المسترشد ليصبح أكثر مسؤولية ويعلمه ويدربه على كيف يضبط ذاته حتى يتمكن من تحقيق صورة ذهنية سليمة . هـ - نظرية العلاج العقلاني العاطفي:

انبثقت نظرية العلاج العقلاني العاطفي على يد مؤسسها ألبرت اليس (Ellis) في أوائل العقد الخامس من القرن العشرين في محاولة منه للمزج بين مدرسة التحليل النفسي والعلاج المتمركز حول المسترشد ومدرسة الجشتالت ويعد هذا الأسلوب من أكثر الأسـاليب العلاجية المعرفيـة شمولية ، فلقد مر تفكير اليس (Ellis) بسلسـة من التطورات خلال حياته المهنية والعلميـة وكانت بداياته الأولى مرتبطة بممارسـة التحليل النفسي إلا انه وجد أن هذا النوع من العـلاج النفسي ليس فعال في مسـاعدة المسترشدين إذ انه وجد أنهح بعد ارتباطهم بالعلاج تسوء حالتهم بدلا من أن تتحسن ، ولم يقتنع أليس (Ellis) باستخدام هذا الاتجاه في العلاج وأصبح أكثر بساطة وايجابية في إيجاد الحلول للمشكلات التي يعاني منها المسترشدون إذ كان يطلب منهم فعل الأمور التي تثعرهم بالخوف ويهابون القيام بها فعلى سبيل المثال الإنسان الذي يخاف من رفض الآخرين لـه خاصـة المقربين لله يطلب منه مواجهة هذا الموقف وتدريجيا يحاول اليس (Ellis) أن يرى الآثار المترتبـة على تلك المـواقف وكيف أن الإنسان مع تغير أفكاره من سلبية إلى ايجابية تتحول سلوكياته أيضا تبعا لذلك (Ellis, 1987, p.211). خطوات الخدمات الارشادية التي يقدمها المرشد وفق نظرية العلاج العقلاني العاطفي : ان دور المرشد النفسي في تفسيره للمشكلات والاضطرابات للأفراد وكيفية علاجها يمكن أن تتضمن الآتي: 1-تقبل فكرة أن الأفراد لديهم القدرات والإمكانات التي تؤهلهم للتصدي للمشكلات السلوكية التي تواجههم. 2-الإدراك بان المشكلات التي يعاني منها الأفراد تتشأ من خلال الأفكار الخاطئة التي يؤمنوا بها. 3-معرفة هذه الأفكار الخاطئة ثم دحضها هي الطريقة المثلى في التغلب على هذه الأفكار. 4-استخدام التفكير العقلاني المنطقي في دحض الأفكار الخاطئة وإحلال الأفكار العقلانية بدلاً منها. 5-تقبل حقيقة أن المسترشدين متى ما كانت لديهم الرغبة في التغيير والعمل على ذلك فإنهم قادرون على مواجهة مشكلاتهم

$$
\text { بفاعلية (الزيود، 1998: 252- 269). }
$$


الدراسات المحلية والعربية والاجنبية التي تتاولت الطموح المهني:

- - ل الوجد دراسة تتاولت متغير الطموح المهني وتعد هذه الدراسة الاولى على مستوى العراق تتاولت عينة المرشدين التربويين.

- - اطلع الباحث على دراسة عربية واحدة فقط تخص مستوى الطموح بصورة عامة لدى عينة المرشدين وهي :

- - دراسة الزهراني (2012) : الرضا عن العمل الارشادي وعلاقته بمستوى الطموح لدى المرشدين الطلابيين بمحافظة جدة .

$$
\text { - - الدراسات المحلية والعربية والاجنبية التي تتاولت الخدمات الارشادية : }
$$

اطلع الباحث على دراسة محلية واحدة فقط تخص الخدمات الارشادية لدى عينة المرشدين التربويين بصورة مباشرة التي تبنى

$$
\text { الباحث مقياسها في الدراسة الحالية وهي: }
$$

- دراسة المعموري (2018) : الخدمات الارشادية وعلاقتها بالأداء الاكاديمي لدى المرشدين التربويين .

\section{الفصل الثالث}

$$
\text { - - منهجية البحث وإجراءاته: - منهجية البحث: - }
$$

استعمل الباحث المنهج الوصفي الارتباطي بوصفه أنسب المناهج لدراسة العلاقات الارتباطية بين المتغيرات من أجل

$$
\text { وصف الظاهرة المدروسة وتحليلها (ملحم، 2000: 32). }
$$

يشتمل مجتمع البحث الحالي على جميع المرشدين التربويين في المدارس المتوسطة والثانوية والإعدادية المشمولة بالإرشاد التربوي في محافظتي واسط وذي قار والبالغ عددهم ( 917) مرشداً ومرشدة الذين يزاولون مهنة الإرشاد في مدارس المديريـة العامـة للتربية محافظة واسط وذي قار حسب الكتب الرسمية الصادرة من المديرية العامـة للتربية محافظة واسط وذي قار قسم التخطيط شعبة الاحصـاء بأعداد المرشدين التربويين ، ولتحقيق هدف البحث الحالي تم اختيار عينة البحث بطريقة عشوائية

$$
\text { والبالغ عددها (200) مرشد ومرشدة . }
$$


للتحقيق اهداف البحث قام الباحث بناء مقياس الطموح المهني وتبني مقياس الخدمات الارشادية لدى المرشدين التربويين قام الباحث بعد اطلاعهم على الأدبيات والدراسات السابقة التي لها علاقة بالطموح المهني والخدمات الارشادية وتوصل الباحث إلى تعريف الطموح المهني بانة (قدرة المرشد التربوي على تحقيق أهدافه المستقبلية في ضوء قدراته وامكاناته في مجال عمله ). وتبنى الباحث مقياس (المعموري ، 2018) ·

ويشير كل من "ألن و ين" ( Allen \& yen) إلى إن عملية بناء أي مقياس ينبغي إن تمر بخطوات أساسية هي :

$$
\begin{aligned}
& \text { - 1 - التخطيط للمقياس - 1 } \\
& \text { 2- جمع وصياغة فقرات المقياس. } \\
& \text { 3- عرض فقرات المقياس على المحكمين • } \\
& \text { 4- تطبيق الفقرات على عينة ممثلة للمجتمع • }
\end{aligned}
$$

5- إجراء تحليل الفقرة (Allen \& yen, 1979:p. 118).

وقد اتبع الباحث هذه الخطوات في عملية بناء المقياس فضلاً عن استخراج خاصيتي الصدق والثبات وكما يأتي :

$$
\text { اولاً / صياغة فقرات للمقياسين : }
$$

1- قام الباحث بصياغة فقرات مقياس الطموح المهني اعتماداً على الدراسات والأدبيات السابقة و المقاييس التي تتاولت مفهوم الطموح بصورة مباشرة أو غير مباشرة ، اما فقرات مقياس الخدمات الارشادية تبني مقياس (المعموري ،2018) للخدمات الارشادية. ثانياً / التحليل المنطقي للمقياسين : بعد أن تم وضـع فقرات مقياس الطموح المهني بصـيغته الأوليـة والبالغـة (20) فقرة ، وفقرات مقياس الخدمات الارشـادية بصيغته الأوليـة والبالغــة (42) فقرة ، وتحديـ بـدائل الإجابـة وطريقـة تصحيـحها ، والدرجـة الموضوعـة لكـل بديـل ، تم عرض 
المقياسين على (10) محكمين من المختصـين في مجال العلوم التربويـة والنفيـة ، للحكم على مدى صلاحيـة كل فقرة في قياس ما وضعت من اجل قياسه مع إبداء الرأي في صلاحية التعليمات وبعد ذلك تم تحليل آراء المحكمين في صـلاحية التعليمات والفقرات إذ اعتمد الباحث نسبة اتفاق (80\% ) فأكثر في تحديد صلاحية الفقرة وبذلك تم الإبقاء على جميع الفقرات للمقياسين •

$$
\text { ثالثاً / تجربة وضوح التعليمات والفقرات وحساب الوقت للمقياسين : }
$$

قيام الباحث بتجربة استطلاعية على عينة صغيرة من مجتمع البحث تتثابه في خصائصها مع عينة البحث الرئيسة وترجع أهمية هذه التجربة إلى تحديد درجة استجابة أفراد العينة والتعرف عما إذا كانت الفقرات وألفاظها في مستوى المفحوصين فضـلاً عن الزمن الذي يتطلبه تطبيق المقياس (فرج، 1980: 111-112). وبعد الانتهاء من إعداد المقياسين بصيغته الأولية ، ولغرض التعرف على وضوح فقرات المقياس وتعليماته وتثخيص اللبس والغموض فيه وحساب الوقت قام الباحث بتطبيقه على (20) مرشد ومرشدة وتبين للباحث ان التعليمات وفقرات المقياسين كانت واضحة ومفهومة من حيث الصياغة والمعنى، وكان الوقت المستغرق للإجابة عن المقياسين تراوح بين( 15-22) دقيقة ، وقد جرت الإشارة إلى أن المقياسين معده لأغراض البحث العلمي فقط لتطمين المستجيبين وحثهم على الإجابة بصدق من دون ذكر الهدف الحقيقي من إجراء القياس ، إذ إن من الأفضل دائمـاً أن لا يوضـح في المقياس ما يشير إلى مـا يقيسه حتى لا يؤثر في صدق

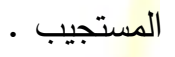

$$
\begin{aligned}
& \text { الخصائص القياسية (السيكومترية ) للمقياسين : } \\
& \text { وقد تحقّق الباحث من الخصائص السيكومترية على النحو الآتي: } \\
& \text { أولاً - صدق المقياسين : } \\
& \text { وللتحقق من صدق المقياسين الحاليين اعتمد الباحث المؤشرات الآتية : }
\end{aligned}
$$

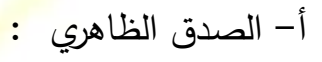

قام الباحث بعرض المقياسين على مجموعة من المحكمين في العلوم التربوية والنفسية للأخذ بآرائهم ، وقد حصلت الفقرات

جميعها على نسبة اتفاق الخبراء تراوحت بين (80\% -100\%) ، واعتمد الباحث موافقـة (8) محكمين معياراً لصـلاحية الفقرة وصدقها في قياس ما وضعت لأجله بنسبة اتفاق الخبراء (80\%) فأكثر ، وتعد نسبة اتفاق (80\%) يعد دليلاً على قبول الفقرة ، 
وبهذا يكون الحكم الصادر منهم مؤشراً على صدق الفقرة ونتيجة ذلك بقى عدد الفقرات مقياس الطموح المهني (20) فقرة ، وعدد

فقرات مقياس الخدمات الارشادية (42) فقرة ، وتحقق هذا النوع من الصدق في المقياسين •

ب- مؤشرات صدق البناء للمقياسين :

أولاً: القوة التمييزية للفترات :

بعد تصحيح استمارات عينة التحليل الاحصائي البالغة (200) استمارة وتم ترتيب الاستمارات بالطريقة التتازلية من اعلى

الىى ادنى درجـة وتم اختيار (27\%) مـن الاستمارات للمجموعـة العليـا البـالغ عددها(54) استمارة و(27\%) مسن الاستمارات

للدجموعة الدنيا والبالغ عددها (54) استمارة أيضاً وتم حساب المتوسطات والانحرافات المعياريـة والقيم التائية لجميع الفقرات وقد

تبين جميع فقرات المقياسين الطموح المهني والخدمات الارشادية كانت مميزة لان القيمية التائية المحسوبة كانت اعلى من القيمية

التائية الجدولية البالغة (1.96) عند مستوى دلالة (0.05) وبدرجة حرية (106) والجدول (1) و(2) يوضح ذلك .

جدول (1) القوة التمييزية لفقرات مقياس الطموح المهني بأسلوب المجموعتين المتطرفتين

\begin{tabular}{|c|c|c|c|c|c|}
\hline \multirow{2}{*}{ 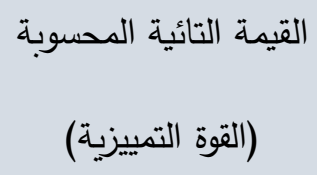 } & \multicolumn{2}{|c|}{ المجموعة الدنيا } & \multicolumn{2}{|c|}{ المجموعة العليا } & \multirow{2}{*}{ الفقرات } \\
\hline & الانحراف المعياري & المتوسط الحسابي & الانحراف المعياري & المتوسط الحسابي & \\
\hline 6,393 & 1,1865 & 2,648 & 1,2185 & 3,694 & 1 \\
\hline 6,607 & 1,1978 & 3,204 & 1,0417 & 4,213 & 2 \\
\hline 9,609 & 1,2211 & 3,389 & 0,6674 & 4,675 & 3 \\
\hline 3,503 & 1,4216 & 3,083 & 1,3745 & 3,750 & 4 \\
\hline 4,237 & 1,2009 & 3,843 & 0,9712 & 4,472 & 5 \\
\hline 7,759 & 1,2164 & 2,344 & 1,3743 & 3,713 & 6 \\
\hline 5,114 & 1,3003 & 2,694 & 1,2540 & 3,583 & 7 \\
\hline
\end{tabular}




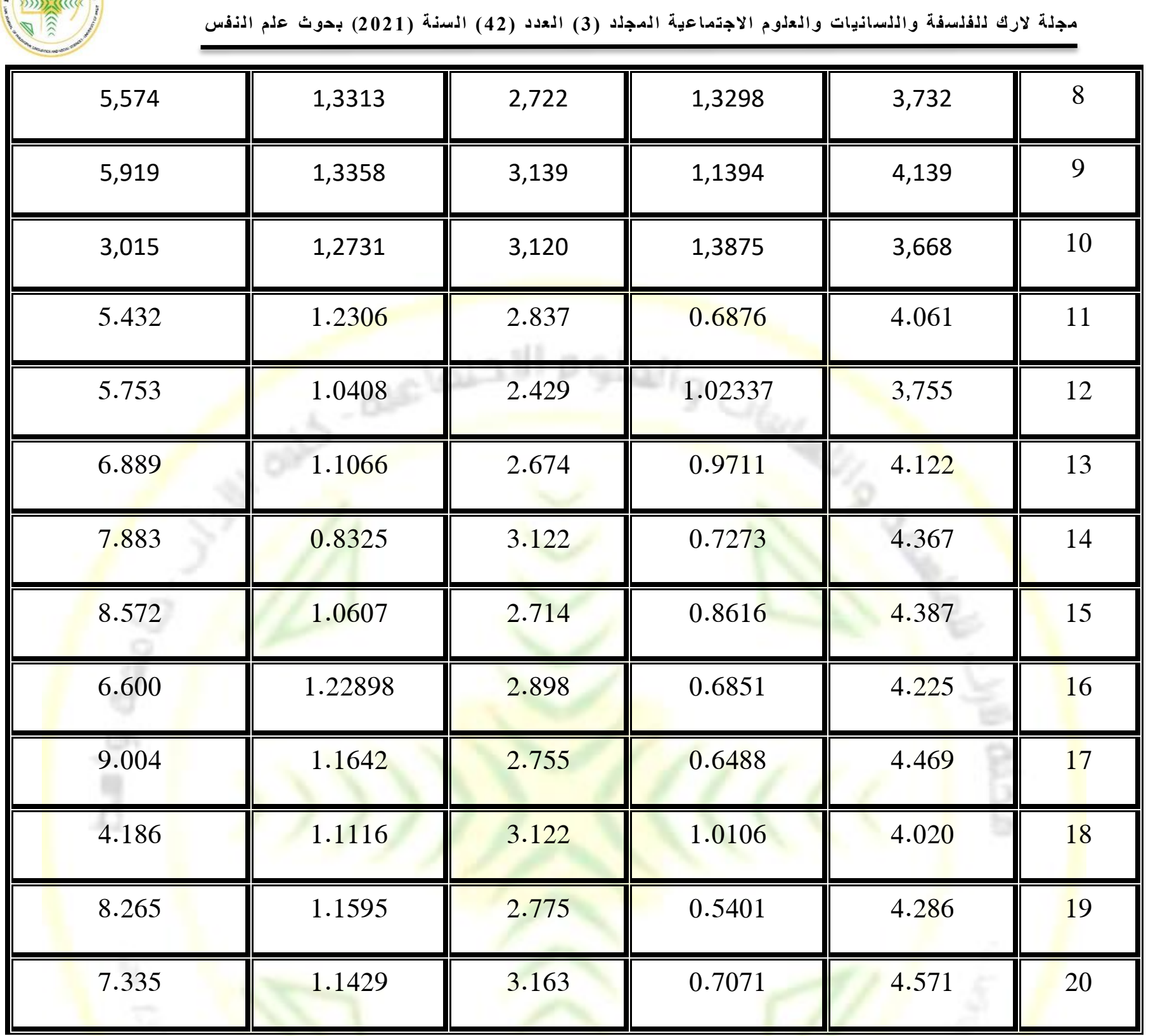

جدول (2) القوة التمييزية لفقرات مقياس الخدمات الارشادية بأسلوب المجموعتين المتطرفتين

\begin{tabular}{|c|c|c|c|c|c|}
\hline \multirow{2}{*}{ القيمة التائية المحسوبة } & \multicolumn{2}{|c|}{ المجموعة الدنيا } & \multicolumn{2}{|c|}{ المجموعة العليا } & \multirow{2}{*}{ الفقرات } \\
\hline & الانحراف المعياري & المتوسط الحسابي & الانحراف المعياري & المتوسط الحسابي & \\
\hline 13,709 & 0,9246 & 1,778 & 0,9834 & 4,296 & 1 \\
\hline
\end{tabular}


مجلة لارك لدفلسفة و اللسدانيات و العلوم الاجتماعية المجلد (3) الـعدد (422) السذة (2021) بحوث علم الذفس

\begin{tabular}{|c|c|c|c|c|c|}
\hline 7,640 & 1,4059 & 2,796 & 0,7700 & 4,463 & 2 \\
\hline 10,588 & 1,0461 & 2,200 & 0,9509 & 4,037 & 3 \\
\hline 5,706 & 1,1492 & 3,003 & 1,0758 & 4,222 & 4 \\
\hline 10,804 & 0,9956 & 1,905 & 1,1035 & 4,093 & 5 \\
\hline $10 ، 823$ & 0,9450 & 1,886 & 1,1763 & 4,111 & 6 \\
\hline 6,213 & 1,2961 & 2,595 & 1,1796 & 4,074 & 7 \\
\hline 4,109 & 0,7670 & 2,571 & 1,7608 & 3,648 & 8 \\
\hline 5,437 & 1,2205 & 2,982 & 0,9983 & 4,148 & 9 \\
\hline 2,507 & 1,4182 & 3,630 & 1,0031 & 4,222 & 10 \\
\hline 2,021 & 1,1059 & 2,852 & 1,4428 & 3,352 & 11 \\
\hline 9,828 & 1,2280 & 2,037 & 1,1393 & 4,278 & 12 \\
\hline 6,991 & 1,2365 & 2,407 & 1,1573 & 4,019 & 13 \\
\hline 5,760 & 1,3929 & 3,056 & 0,8468 & 4,333 & 14 \\
\hline 7,092 & 1,2196 & 2,611 & 1,0829 & 4,185 & 15 \\
\hline 5,391 & 1,2689 & 3,222 & 0,8722 & 4,352 & 16 \\
\hline 7,057 & 1,4325 & 2,796 & 0,945 & 4,444 & 17 \\
\hline 9,587 & 0,9098 & 3,242 & 0,4960 & 4,593 & 18 \\
\hline 4,894 & 1,2896 & 2,815 & 1,2663 & 4,019 & 19 \\
\hline 10,132 & 1,0614 & 2,074 & 1,04694 & 4,130 & 20 \\
\hline
\end{tabular}


مجلة لارك لدذلسفة و الذسدانيات و العلوم الاجتماعية المجلد (3) الـعدد (422) السذة (2021) بحوث علم الذفس

\begin{tabular}{|c|c|c|c|c|c|}
\hline 8,400 & 1,2173 & 1,907 & 1,1881 & 3,852 & 21 \\
\hline 7,544 & 1,5681 & 2,352 & 1,1863 & 4,370 & 22 \\
\hline 5,494 & 0,9877 & 3,074 & 1,0772 & 4,167 & 23 \\
\hline 5,085 & 1,0766 & 3,463 & 0,8817 & 4,426 & 24 \\
\hline 8,463 & 1,426 & 2,426 & 0,943 & 4,574 & 25 \\
\hline 7,103 & 1,2534 & 2,296 & 1,2663 & 4,019 & 26 \\
\hline 8,717 & 1,2837 & 2,222 & 1,0932 & 4,222 & 27 \\
\hline 3,490 & 1,1230 & 2,722 & 1,4974 & 3,611 & 28 \\
\hline 5,082 & 1,4109 & 2,167 & 1,3139 & 3,500 & 29 \\
\hline 7,075 & 1,1228 & 2,148 & 1,1883 & 3,722 & 30 \\
\hline 8,689 & 1,1059 & 1,852 & 1,2799 & 3,851 & 31 \\
\hline 9,329 & 1,1271 & 2,444 & 0,9935 & 4,352 & 32 \\
\hline 5,986 & 1,4775 & 2,074 & 1,3150 & 3,685 & 33 \\
\hline 2,787 & 1,1883 & 3,389 & 1,2280 & 4,037 & 34 \\
\hline 7,388 & 1,1396 & 2,389 & 1,2040 & 4,056 & 35 \\
\hline 4,324 & 1,3122 & 2,704 & 1,2689 & 3,778 & 36 \\
\hline 6,632 & 1,2108 & 3,074 & 0,8817 & 4,426 & 37 \\
\hline 2,486 & 1,2229 & 3,296 & 1,2539 & 3,889 & 38 \\
\hline 4,850 & 1,38278 & 2,778 & 1,1894 & 3,982 & 39 \\
\hline
\end{tabular}


مجلة لارك لدذلسدفة واللسدانيات واللعلوم الاجتماعية المجلد (3) العدد (42) السدة (2021) بحوث علم الذفس

\begin{tabular}{|c||c|c|c||c||c|}
\hline 6,135 & 0,9791 & 3,148 & 1,0279 & 4,333 & 40 \\
\hline \hline 2,446 & 0,9792 & 3,148 & 1,4198 & 3,722 & 41 \\
\hline \hline 3,165 & 0,9792 & 3,148 & 1,1987 & 3,815 & 42 \\
\hline
\end{tabular}

ثانياً: علاقة درجة الفقرة بالدرجة الكلية للمقياسين:

يعني هذا أن الفقرة تقيس المفهوم نفسه الذي يقيسه الدقياس كلياً إذ يعد هذا احد مؤشرات صدق البناء(الزوبعي ، الحمداني

1983 : 43). وقد تحقق هذا النوع من الصدق في مقياس الطموح المهني والخدمات الارشادية ، من خلال استخدام معامل

ارتباط بيرسون لاستخراج العلاقة الارتباطية بين درجة كل فقرة والدرجة الكلية لـ(200) استمارة ، وقد تبين ان جميع الارتباطات

دالة لاى مقارنتها بالقيمة الجدولية البالغة ( 0.139) عند مستوى دلالة (0.05) وبدرجة حرية(198) وجدول (3) و(4) يوضح

الجدول(3) قيم معاملات ارتباط الفقرات بالدرجة الكلية لمقياس الطموح المهني

\begin{tabular}{|c|c|c|c|c|c|}
\hline معالمل ارتباط الفقرة & رقفر & معالمل ارتباط الفقرة & رقم الفقرة & معالمل ارتباط الفقرة & رقفم \\
\hline 0,407 & 15 & 0,255 & 8 & 0,537 & 1 \\
\hline 0,253 & 16 & 0,386 & 9 & 0,424 & 2 \\
\hline 0,395 & 17 & 0,402 & 10 & 0,479 & 3 \\
\hline 0,241 & 18 & 0,482 & 11 & 0,408 & 4 \\
\hline 0,423 & 19 & 0,195 & 12 & 0,403 & 5 \\
\hline \multirow[t]{2}{*}{0,492} & \multirow[t]{2}{*}{20} & 0,271 & 13 & 0,277 & 6 \\
\hline & & 0,261 & 14 & 0,398 & 7 \\
\hline
\end{tabular}

الجدول (4) قيم معاملات ارتباط الفقرات بالدرجة الكلية لمقياس الخدمات الارشادية

\begin{tabular}{|c|c|c|c|c|c|}
\hline بالدرجة الكلية ارتباط الفقرة & الفقرة & معامل ارتباط الفقرة & رقم الفقرة & معامل ارتباط الفقرة & الفقرة \\
\hline 0,631 & 29 & 0,338 & 15 & 0,241 & 1 \\
\hline
\end{tabular}




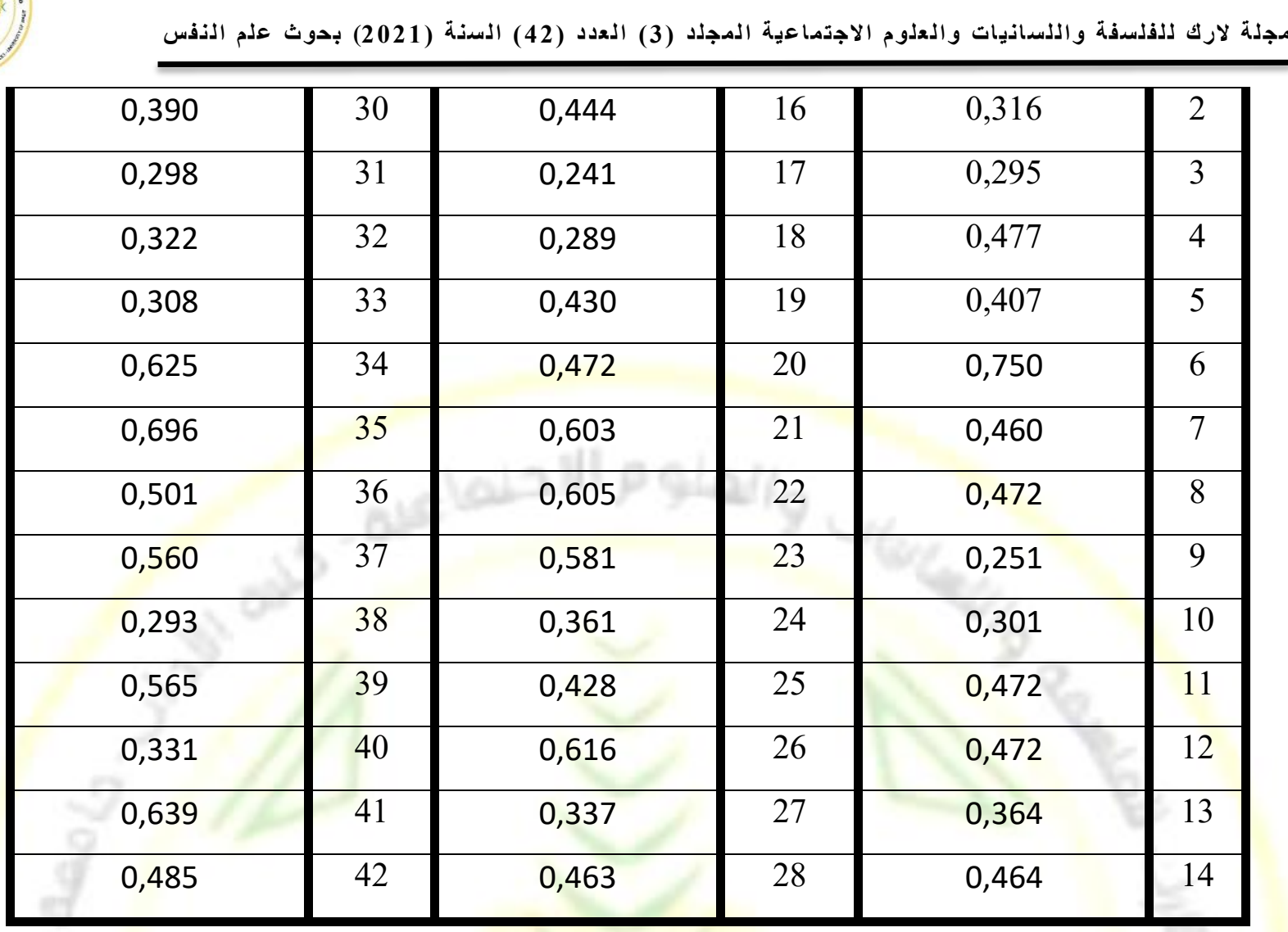

ثالثاً: علاقة درجة الفقرة بدرجة المجال الذي تتنمي اليه لمقياس الخدمات الارشادية:

لتحقيق ذلك أستعمل الباحث معامل ارتباط بيرسون لاستخراج العلاقة الارتباطية بين درجة كل فقرة من فقرات المقياس والدرجة الكلية للمجال الذي تتتمي إليه، وقد كانت جميع معاملات ارتباط الفقرات دالة إحصائياً عند مستوى دلالة(0.05) وبدرجة حرية(198)، أذ ان معاملات الارتباط المحسوبة لجميع الفقرات كانت أكبر من القيمة الحرجة لمعامل الارتباط والبالغة(0.139) كما موضح في الجدول(7).

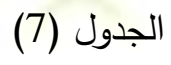

قيم دعامل ارتباط بيرسون بين الفقرات والمجال الذي ينتمي إليه لمقياس الخدمات الارشادية

\begin{tabular}{|c|c|c|c|c|c|c|c|c|}
\hline معامل الارتباط & الفقرة & المجال & الارتباط & الفقرة & المجال & الارتباط & الفقرة & المجال \\
\hline 0,305 & 1 & $\bar{x} \bar{y}$ & 0.408 & 1 & $\bar{x} \overline{7}$ & 0,659 & 1 & \multirow{2}{*}{ 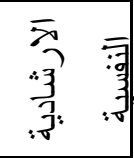 } \\
\hline 0,359 & 2 & :3. & 0.200 & 2 & "3. & 0,627 & 2 & \\
\hline
\end{tabular}


مجلة لارك لدلذسفة واللسانيات والعلوم الاجتماعية المجلد (3) العدد (42) السذة (2021) بحوث علم الذفس

\begin{tabular}{|c|c|c|c|c|c|}
\hline 0,252 & 3 & 0.398 & 3 & 0,441 & 3 \\
\hline 0,505 & 4 & 0,540 & 4 & 0,274 & 4 \\
\hline 0,387 & 5 & 0,390 & 5 & 0,560 & 5 \\
\hline 0,434 & 6 & 0,301 & 6 & 0,262 & 6 \\
\hline 0,465 & 7 & 0,492 & 7 & 0,357 & 7 \\
\hline 0,696 & 8 & 0,521 & 8 & 0,716 & 8 \\
\hline 0,622 & 9 & 0,474 & 9 & 0,707 & 9 \\
\hline 0,344 & 10 & 0,335 & 10 & 0,351 & 10 \\
\hline 0.499 & 11 & 0,416 & 11 & 0,314 & 11 \\
\hline 0.517 & 12 & 0,248 & 12 & 0,494 & 12 \\
\hline & & 0,333 & 13 & 0.200 & 13 \\
\hline & & 0.299 & 14 & 0.331 & 14 \\
\hline t & & 0.443 & 15 & 0.395 & 15 \\
\hline
\end{tabular}

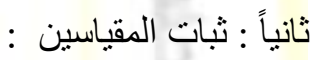

وللكثف عن مؤشرات ثبات المقياسين الحالي اعتمد الباحث الطريقة الآتية : أ- الاتساق الخارجي باستعمال طريقة الاختبار - إعادة الاختبار للمقياسين:

ولحساب الثبات بهذه الطريقة قام الباحث بتطبيق مقياسي (الطموح المهني والخدمات الارشادية) على عينة من المرشدين التزبويين بلغت (35) مرشد ومرشدة ثم تم إعادة تطبيق الدقياسين بعد مرور أسبوعين وحسب معامل ارتباط بيرسون بين درجات التطبيق الأول والتطبيق الثاني، وبلغ معامل الارتباط بالنسبة لمقياس الطموح المهني (0,79)، أما مقياس الخدمات الارشادية فقد بلغ معامل الارتباط بهذه الطريقة (0,80) وهو ثبات جيد حسب راي انستازي (Anastasi,1988,P.126). ب-اتساق الداخلي باستعمال معامل ألفا كرونباخ للمقياسين : ولأجل استخراج الثبات بهذه الطريقة تم تطبيق مقياسي (الطموح المهني والخدات الارشادية) على عينة مكونة من (35) مرشد وكانت قيمة معامل الثبات لمقياس الطموح المهني هي (0,77) ، وكانت قيمة معامل الثبات لمقياس الخدمات الارشادية هو 
وصف المقياسين بصيغته النهائية:

ا- مقياس الطموح المهني :

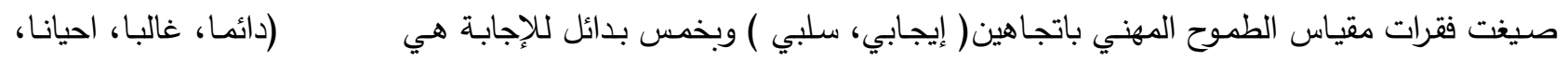

نـادرا، ابـدا) ، وقد أعطيت الأوزان( 5 ، 4 ، 3 ، 2 ، 1 ) بالنسبة للفقرات الإيجابيـة، والأوزان ( 1 ، 2 ، 3 ، 4 ، 5 ) بالنسـبة للفقرات السلبية ، وبذلك تكون أعلى درجة يحصل عليها المستجيب هي ( 100) درجة ، وأقل درجة يحصل عليها هي(20) درجة، علماً إن المتوسط النظري للمقياس بلغَ (60) درجة.

2-مقياس الخدمات الارشادية :

يتكون الخدمات الارشـادية الجامعي من (42) فقرة موزعـة علـة ثـلاث مجالات هي (الخدمات الارشـادية النفسية ، الخدمات

الارشادية التربويـة ، الخدمات الارشادية الاجتماعية) وباتجاه ايجابي فقط وبخمس بدائل للإجابة هي (دائما، غالبا، احيانا، نادرا،

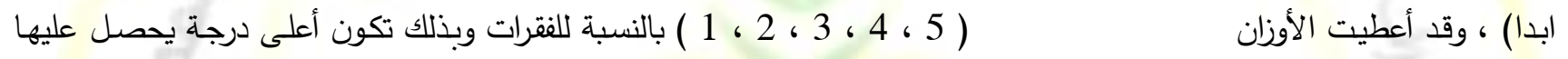
المستجيب هي( 210) درجة، وأقل درجة يحصل عليها هي(42) درجة، علماً إن المتوسط النظري للمقياس بلغَ (126) درجة. الوسائل الاحصائية:

لمعالجة بيانات البحث، استعمل الباحث الوسائل الاحصائية المناسبة بمساعدة الحقيبة الإحصائية (SPSS) بواسطة الحاسوب. الفصل الرابع

عرض نتائج البحث ومناقشتها:

الهدف الأول : التعرف على درجة الطموح المهني لاى المرشدين التربويين :

لتحقيق هذا الهدف طبق الباحث مقياس الطموح المهني على عينة البحث البالغ عددهم (200) مرشد ومرشدة ، وقد

اظهـرت نتـائج التطبيـق النهـائي ان المتوسـط الحســي لـدرجات افـراد العينـة قـــــــ (39.900) وبـانحراف معيـاري مقـداره

(6.08829) درجة ، في حين كان المتوسط الفرضي للمقياس (60) درجة ، ولمعرفة الفرق بين المتوسطين استعمل الباحث

الاختبار التائي لعينة واحدة وتبين ان القيمة التائية المحسوبة البالغة (46.636-) درجة هي اصغر من القيمة التائية الجدولية

البالغة (1.96) وبدرجة حرية (199) وهي ذات دالة احصائية عند مستوى دلالة (0.05)، والجدول (1) يوضح ذلك . 
جدول (1) نتائج الاختبار التائي لدلالة الفرق بين المتوسط الحسابي والانحراف المعياري والمتوسط الفرضي لمقياس الطموح

المهني

\begin{tabular}{|c|c|c|c|c|c|c|}
\hline \multicolumn{2}{|c|}{ القيمة التائية } & المتوسط & الأنحر اف & المتوسط & & \\
\hline الجدولية & المحسوبة & النظري & المعياري & الحسابي & & \\
\hline 1.69 & -46.636 & 60 & 6.08829 & 39.900 & 200 & الطموح المهني \\
\hline
\end{tabular}

وتثير هذه النتيجة الى أن متوسط درجات الطموح المهني هو أقل من المتوسط الفرضي للمقياس ، وهذا يعني ان المرشدين التربوين لديهم انخفاض في تحقيق طموحهم المهني في مجالهم الارشادي ، ويرى الباحث ان النتيجة منطقيه مع الواقع الفعلي الي يواجه المرشدين التربوين من معاناة كبيرة في بيئتهم المهنية من تهميش وعدم تقدير والعزلة والتدخل المستمر في عملهم من قبل إدارة المدرسـة ، فضـلا عن ضـفف المساندة والدعم المقدم اليهم من قبل المسؤولين في وزارة التربية تشعرهم بالإحباط لتحقيق طموحهم المهني. الهدف الثاني : التعرف على درجة الخدمات الارشادية : لتحقيق هذا الهدف طبق الباحث مقياس الخدمات الارشادية على عينة البحث البالغ عددهم (200) مرشد ومشدة ، وقد اظهرت نتائج التطبيق النهائي ان المتوسط الحسابي لدرجات افراد العينة قد بلغ (84.161) وبانحراف معياري مقداره (26.567) درجة ، في حين كان المتوسط الفرضي للمقياس (126) درجة ، ولمعرفة الفرق بين المتوسطين استعمل الباحث الاختبار التائي لعينة واحدة وتبين ان القيمة التائية الدحسوبة البالغة (3.367-) درجة هي اصغر من القيمة التائية الجدولية البالغة (1.96) وبدرجة حرية (199) وهي ذات دالة احصائية عند مستوى دلالة (0.05)، والجدول (2) يوضح ذلك . 
جدول (2)نتائج الاختبار التائي لدلالة الفرق بين المنوسط الحسابي و الانحر اف المعياري و المنوسط الفرضي لمقياس الخدمات الارشادية

\begin{tabular}{|c|c|c|c|c|c|c|}
\hline \multicolumn{2}{|c|}{ القيمة التائية } & المتوسط & الأنحر اف & المتوسط & & \\
\hline الجدولية & المحسوبة & النظري & المعياري & الحسابي & & \\
\hline 1.69 & -3.367 & 126 & 26.567 & 84.161 & 200 & الخدمات الارشادية \\
\hline
\end{tabular}

وتثير هذه النتيجة الى أن متوسط درجات الخدمات الارشادية هو أقل من المتوسط الفرضي للمقياس ، وهذا يعني أن المرشدين التربوين لديهم ضعف في تقديم الخدمات الارشادية بشكلها الصحيح والفعال ، ويرى الباحث ان المرشدين التربوين غير قادرين على تطبيق المهام المناط اليهم بشكل واضتح وناضـج بسبب زجهم في اعمال خارج تخصصهم منها اداريـة أو مكتبية ، بالإضافة الى ان الكثير من المرشدين النفسيين يعانون من مشكلات مع ادارات المدارس والسبب هو عدم تقدير أو فهم لمهنتهم من قبل مدراء المدارس وكذلك التدريسيين المتواجدين معهم في المدرسة بالإضـافة الى صعوبات أخرى تواجه المرشدين النفسيين منها الزيادة الحاصلة في اعداد الطلبة ، وكذلك تقصير اولياء امور الطلبة في متابعة ابنائهم وعدم وجود غرفة خاصـة لأغلب المرشدين التربوين ، وكل هذه الاسباب وغيرها تحول دون اداء عمل المرشد بشكل فعال ، وهذه النتيجة اختلفت عن نتائج دراسة (المعموري ، 2018). الهدف الثالث : التعرف على العلاقة بين الطموح المهني والخدمات الارشادية لدى المرشدين التربويين : لتحقق من الهدف الثالث الذي يتضـن تعرف العلاقة بين درجات الطموح المهني والخدمات الارشـادية لدى المرشدين التربويين ، قام الباحث بتطبيق معامل ارتباط بيرسـون بين الدرجة الكلية لأفراد العينة على مقياسين البحث الطموح المهني والخدمات الارشـادية ، فبلـغ معامل الارتباط بينهما (263, 0) درجـة ، وبعد تطبيق الاختبار التائي لدلالـة معاملات الارتباط ظهر أن القيمة التائية المحسوبة البالغة (5,438) درجة هي اكبر من القيمة الجدولية البالغة ( 1,96) درجة عند مستوى دلالة (0,05) وبدرجة حرية (198) مما يشير إلى أن هناك علاقة موجبة ودالة إحصائيا بين درجات متغيري البحث الطموح المهني والخدمات الارشادية والجدول (3) يوضح ذلك:

الجدول (3) معامل الارتباط والقيمة التائية بين متغيري الطموح المهني والخدمات الارشادية لدى المرشدين التربويين 
مجلة لارك للفلسدفة واللسدانيات والـعلوم الاجتماعية المجلد (3) العدد (42) السدة (2021) بحوث علم الذفس

\begin{tabular}{|c|c|c|c|c|c|}
\hline مستوى & \multicolumn{2}{|c|}{ القيمة التائية } & \multirow{2}{*}{ الحرجة } & \multirow{2}{*}{ قالطموح المهني والخدمات الارشادية } & \multirow{2}{*}{ العدد } \\
\hline (الدلم) & الجدولية & المحسوبة & & & \\
\hline دالة & 1,96 & 5,438 & 198 & 0,263 & 200 \\
\hline
\end{tabular}

إذ تدل هذه النتيجة على إن المرشدين التربويين لايهم انخفاض في تحقيق طموحهم المهني وكذلك لديهم ضعف في تقديم

الخدمات الارشادية بثكلها الصحيح والفعال ، ومعنى هذا إن الطموح المهني له علاقة موجبة وطردية بالخدمات الارشادية ، أي كلما انخفض الثعور بالطموح المهني انخفضت معه الخدمات الارشادية والعكس صحيح ويمكن تفسير هذه النتيجة على أن العلاقة الارتباطية بين متغيري البحث علاقة دالة وموجبة أي أن المتغيرين مرتبطان مع بعضهما البعض ، و يمكن من خلال معرفة احدهما التنبؤ بمستوى المتغير الأخر ، وتتفق هذه النتيجة مع نتائج كلاً من دراسة الزهراني ، 2012) ودراسة (المعوري ، 2018).

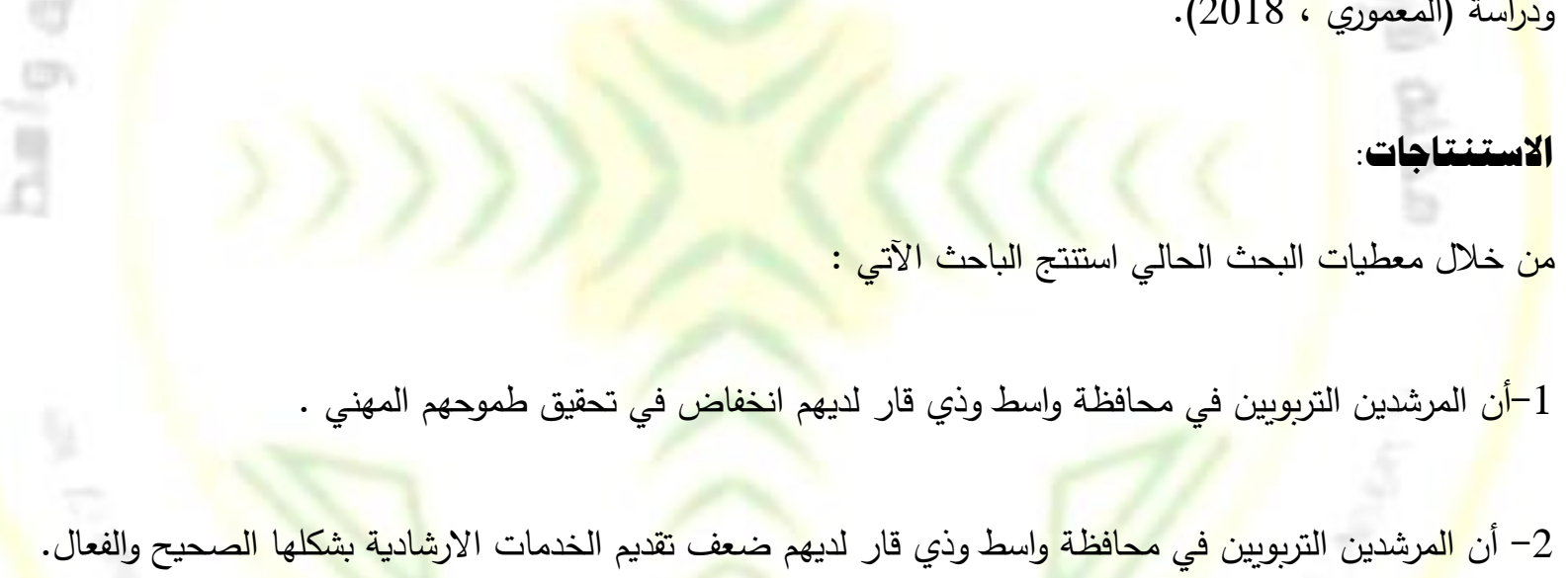

3-توجد علاقة ارتباطية طردية بين درجات الطموح المهني والخدمات الارشادية لدى المرشدين التربويين محافظة واسط وذي قار.

\section{التوصيات :}

في ضوء النتائج التي تُّم التوصل اليها البحث الحالي يوصي الباحث بما يأتي:

1- ضرورة اهتمام وزارة التربية بمكانة المرشد التربوي وابراز دوره المهني من خلال تقديم كل عوامل نجاح العملية الارشادية. 
2- ضرورة توفير مكتبة ارشادية تظم في ثناياها العديد من المقاييس والبرامج الارشادية للاستفادة منها وبحسب ما يمليه عليه

الموقف الارشادي ذي الطبيعة العلمية والانسانية.

3- توفير اجهزة التكنولوجيا الحديثة والتي تدعم وتكلل عمل ونجاح مهام المرشد التربوي.

4- ضرورة تكثيف الجهود المختلفة لتأسيس جمعية مهنية إرشادية متخصصة تجمع المرشدين التربويين في كل محافظة لكي

$$
\text { تزودهم بحس الانتماء المهني وتمكنهم من تبادل الرأي والخبرة. }
$$

5- عدم تكليف المرشد النفسي المدرسي بأعمال إدارية ليس لها علاقة بدوره الإرشادي في المدرسة حتى لا تعطله عن القيام بهذا الدور.

6- العمل على إقامة دورات إرشادية التي تقوم على توعية المرشدين التربويين وخاصة الذين ليس لديهم الخدمة والخبرة الكافية. 7- زيادة أعداد المرشدين النفسيين التربويين في المدارس حتى تتوفر فرص أفضل للمرشد النفسي ليقوم بدور فعال مـع عدد محدود من الطلاب.

\section{الاقترحات :}

يقترح الباحث في ضوء النتائج والتوصيات مايأتي : 1- بناء برامج ارشادية للمرشدين تقدم من خلالها احدث الاساليب الارشادية والتي بدورها تعمل على رفع الاداء الاكاديمي لدى المرشدين التربوين لتقديم افضل الخدمات الارشادية وتتمية الطموح المهني لديهم .

2- إجراء دراسة تبحث في العلاقات بين الطموح المهني ومتغيرات نفسية وتربوية أخرى ، مثل ، مواجهه الضغوط ، التفكير

$$
\text { الايجابي ، تتظيم الذات للى المرشدين التربوين • }
$$

3- إجراء دراسة تبحث في العلاقات بين الخدمات الإرشادية ومتغيرات نفسية وتربوية أخرى ، مثل، الكفاية الذاتية - توكيد

$$
\text { الذات - سمات الثخصية - الرضا الوظيفي لدى المرشدين التربويين. }
$$

\section{هصادر البحث العربية والاجنبية}

• أبو اسعد ، احمد عبد اللطيف (2011): العملية الارشادية ، دار المسيرة للنشر والتوزيع ، ط1، عمان ، الاردن • • أبو عيطة، سهام درويش(1988):نظريات الإرشاد والتوجيه التربوي، مكتبة الانجلو، مصر • 
• الأسدي ، سعد جاسم (2001) : التعرف ميدانياً على اسهامات المرشد التربوي في توجيه الطلبة مهنيا ، مجلة العلوم

$$
\text { التربوية والنفسية ، العدد(41). }
$$

البادري ، سعود بن مبارك (2011) : تطبيقات في علم النفس مهنة وتربية ، ط1 دار الكتاب الجامعي ، العين ، الامارات

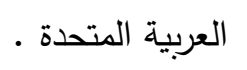

جبريل، موسى (1992): التكيف والرعاية الصحية والنفسية، منشورات جامعة القدس المفتوحة، عمان. • جريو ، صادق كاظم (2001) : دراسة مقارنة في مستوى الطموح والتحصيل الدراسي عند طلبة الدراستين الصباحية والمسائية ، (رسالة ماجستير غير منشورة) ، جامعة بغداد.

الخواجا ، عبد الفتاح محمد (2009): الارشاد النفسي والتربوي بين النظرية والتطبيق ، دار التقافة للنشر والتوزيع ، عمان ، • 1 الاردن

•الزبيدي ، سلمان عاشور مجلي (2001): المدخل الى التوجيه والارشاد ، دار الكتب الوطنية ، بنغازي ، ليبيا . زهران ، حامد عبد السلام (1988) : التوجيه والإرشاد النفسي ، عالم الكتب ، ط2 ، القاهرة ، مصر. الزهراني، سعيد بن ابراهيم بن احمد (2012) : الرضا عن العمل الارشادي وعلاقته بمستوى الطمح للى المرشدين الطلابيين ، (رسالة ماجستير ) ، جامعة الملك عبد العزيز ، المملكة العربية السعودية. الزوبعي ، عبد الجليل والحمداني ، موفق (1983): بناء الاختبار ، جامعة الموصل ، العراق • الطوالبة ، محمد عبد الرحمن (2000) : الرضا عن العمل لدى معلمي ومعلمات الحاسوب في المدارس الحكومية الأردنية ، مجلة مركز البحوث التربوية بجامعة قطر ، العدد(12) ، السنة التاسعة. فرج ، صفوت (1980) : التحليل العاملي في العلوم السلوكية ، دار الفكر العربي ، القاهرة. القطاني ، علاء سمير موسى (2011) : الحاجات النفسية ومفهوم الذات وعلاقتهما بمستوى الطموح لدى طلبة جامعة الازهر بغزة في ضوء نظرية محددات الذات ، (رسالة ماجستير غير منشورة) ، جامعة الازهر ، كلية التربية . • محمد، عبد الحميد عثمان (2001): تقارير الكفايــة المهنيــة ،مركز الدراسات القانونية، كلية الحقوق، جامعة أسيوط . • محمود، شريف مهني (2001) : دراسة الاغتراب وعلاقته بمستوى الطموح لدى طلاب الثانوي العام والفني والصناعي ، (رسالة ماجستير غير منشورة) ، كلية التربية ، جامعة عين شمس ، القاهرة . 
• المعموري، حسن ابراهيم (2018) : الخدمات الارشادية وعلاقتها بالأداء الاكاديمي لدى المرشدين التربوين، (رسالة ماجستير غير منشورة) ، كلية التربية / ابن رشد للعلوم الانسانية ، جامعة بغداد.

ملحم، سـامي محمد (2000): القيــاس والتقويم في التربيـــة وعلم النفس، دار المسيرة، للتوزيـع والنشـر، ط1، عمـان ، - الأردن

النمري ،عبد الرزاق محمد احمد (1997): الكفاءات المهنيـة والرضـــا الوظيفي لخريجي التعليم الفني بالمملكة العربيـة السعوديــة، (رسـاسـة ماجستير غير منشورة)، جامعة ام القرى مكة المكرمة .

- Allen, M. J\&Yen.W. M(1979):Introduction to measurement Theory . California, Book Cole .

- Anastasi , Ame . (1988): Psychological testing, New York the MacMillan Company.

- Bandura, A . (1997). Self Efficacy. The Exercise of Control, New York : W.H. freeman.

- Eble, R. L (1972): Essentials of education measurement Ed, practice hall Englewood cliffs. New Jersey .

- Ellis, Albert, and Griegers Russel(1987):Hand book of rational emotive, therapy , spring republishing company new york.

- Lafleur, M. K (1979): Behavioral views of counseling, in: Burks \& stefflre (eds) Theories of counseling, Mggraw - hil, CO.

- Shilling, L.e., (1984) Perspectives on counseling Theroies, prentice - hall, ins, New jersey. 